\title{
BOND REFUNDING IN EFFICIENT MARKETS: A DYNAMIC ANALYSIS WITH TAX EFFECTS
}

\author{
Raymond C. Chiang \\ University of Miami \\ M. P. Narayanan \\ The University of Michigan
}

\begin{abstract}
This paper provides a dynamic analysis of the bond refunding problem in an efficient market setting with corporate taxes and transaction costs. A new methodology is developed to analyze the optimal exercise problem in the presence of imperfections. This analysis enables prediction of the effect of changes in corporate tax laws on the refunding decision. It also explains the empirical observation that bonds are often called when the bond price is below the call price.
\end{abstract}

\section{Introduction}

The literature on bond refunding can be broadly classified into two categories: (1) static models (e.g., Bowlin (1966), Ofer and Taggart (1977), Yawitz and Anderson (1977), Lewellen and Emery (1980)), and (2) dynamic models (e.g., Bierman (1966), Brennan and Schwartz (1977), Kalymon (1971), Kraus (1973), Pye (1966), Weingartner (1967)). Static models do not consider whether it is more profitable to wait and refund at some future period; that is, they do not address optimal refunding time. These models implicitly assume that the option to call expires if unexercised in the period under consideration. Dynamic models, on the other hand, address the optimal refunding time. Unlike the static models of Ofer and Taggart (1977), Yawitz and Anderson (1977), and Lewellen and Emery (1980) that use an efficient market setting (a Modigliani-Miller world with taxes) and shareholder wealth maximization to derive refunding criteria, the dynamic models (except Brennan and Schwartz (1977)) derive their criteria based on "debtcost" minimization. If markets are efficient, debt-cost minimization is not consistent with shareholder wealth maximization. Moreover, the dynamic models (except Kraus (1973)) do not explicitly use the efficient markets assumption. Also, all of the dynamic models (including Brennan and Schwartz (1977)) ignore the impact of corporate taxes on the refunding decision. ${ }^{1}$

The authors thank Anand Desai for advice on computational aspects and $M$. Nimalendran for assistance with the graphics software. They also thank two anonymous referees for their extensive comments, while retaining responsibility for any errors.

${ }^{1}$ Constantinides and Grundy (1987) analyze the optimal call policy of convertible bonds in a world of corporate taxes. They do not, however, consider stochastic interest rates. 
This paper integrates the approaches of these two classes of papers by providing a dynamic analysis of the bond refunding problem in an efficient market setting with corporate taxes and transaction costs. As in the static models, shareholder wealth maximization is used as the firm's objective. Unlike previous dynamic models, the efficient market assumption is fully exploited to simplify the analysis. The efficient market assumption allows relaxation of the risk-neutrality assumption that is employed in most dynamic models. Moreover, the refunding criterion is shown, in principle, to be independent of the type of stochastic process followed by interest rates (or other state variables). ${ }^{2}$ This is achieved by stating the refunding criterion in terms of the current prices of the securities instead of interest rates, since in efficient markets current prices reflect all information regarding investors' expectations about future interest rates.

Taxes affect the refunding decision through interest tax shields and the call premium tax shield. The corporate tax rate is found to have little effect on the critical interest rate (the rate at or below which it is optimal to refund) at longer times to maturity. At shorter times to maturity, a decrease in the tax rate reduces the critical interest rate. Thus, ceteris paribus, firms that do not expect to pay taxes in the near future are less likely to refund a bond.

When imperfections like taxes and transaction costs are considered, the value of the bond at the critical interest rate need not equal the call price. This is consistent with $\mathrm{Vu}$ (1986) who finds that few bonds are priced at the call price one month before the call. Most of the bonds in his sample are priced below the call price one month before the call.

This paper provides a methodology for solving problems involving optimal exercise of options when there are imperfections such as taxes and transaction costs. The current optimal call policy depends on the value of the bond and the value of imperfections conditional on the current call decision. Since the conditional values of the bond and the imperfections at any point depend only on the state variables, time, and the optimal future call decisions, they can be valued like any security if future call policy (as a function of the state variable) is known. Therefore, the conditional values of the bond and the imperfections are determined using future call policies and these values are used to determine simultaneously the current call policy and the (unconditional) value of the bond. This methodology differs from that of Brennan and Schwartz (1977) in its use of synthetic securities representing the conditional values of the bond and the imperfections, and it is more general as it can accommodate imperfections. ${ }^{3}$ It can be used for any optimal exercise problem (like valuing put options or American calls) involving imperfections that depend on the optimal exercise policy.

\footnotetext{
${ }^{2}$ While the stochastic process the interest rates follow does not affect the principle behind the refunding criterion, it certainly affects the implementation. See the Appendix for details.

${ }^{3}$ Dunn and Spatt (1986) use a similar methodology in their paper. Their model, however, ignores taxes. Brennan and Schwartz (1977) do not consider any imperfections in their paper.
} 


\section{Decision Rules for Refunding}

\section{Setting}

All bonds are assumed perpetual. Callable bonds issued by firms can be called only at discrete points in time, that, for convenience, are assumed to be the points when interest payments are due. At each point the firm pays the interest due that period; it then has the choice of exercising its call option. If the firm forgoes its option to call in any period, it must wait until the next period to exercise that option again. If the firm does call the bond, paying the call price, it replaces the old issue with another bond issued at par. ${ }^{4}$

The face value of the new bond, and hence the total amount raised, depends on what is called the capital structure objective of the firm. Some capital structure objective is needed to analyze the refunding problem with corporate taxes. If the analysis is done under the assumption of perfect capital markets (as in Brennan and Schwartz (1977)), there is no need for any such objective since capital structure is irrelevant. Ideally, the refunding operation should optimize the capital structure. However, since the solution to the optimal capital structure problem is still elusive, researchers tackle the refunding problem under various capital structure objectives, the most commonly employed of which are: (a) keeping the face value of the debt constant (see, for example, Ofer and Taggart (1977)); (b) keeping the interest payments the same (see Yawitz and Anderson (1977), Lewellen and Emery (1980)); and (c) increasing the face value just enough to pay, above the face value of the old issue, the call premium and any refunding costs (see Bierman (1966), Ofer and Taggart (1977)). The merits of the various capital structure objectives are not discussed since such a discussion is futile without a formal theory of optimal capital structure. For the analysis here objective (c) is chosen with a slight modification. The face value of the replacement bond is assumed to equal the call price of the original bond and the transaction costs involved in the refunding process are assumed to be paid from internal funds. The refunding criterion using objective (b) is analyzed in the next section and it is shown that it is a simpler version of the criterion using objective (c). Since the price of the callable bond equals the call price if refunding is optimal, the use of objective (c) ensures that the market value of debt is unaffected by refunding. Therefore, the effects of refunding are not confounded by the effects, if any, of changes in the market value of debt.

Markets are assumed to be efficient. The capital structure objective of the firm is further assumed to be common knowledge. Since the bond refunding decision is based on published information (on market parameters such as rate of interest and on bond parameters such as coupon rate, call premium), the efficiency assumption implies that rational bond refunding decisions do not affect shareholder wealth. ${ }^{5}$

${ }^{4}$ If the replacement bond is not issued at par it only complicates the algebra without any impact on the results.

${ }^{5}$ That rational refunding decisions do not affect stockholder wealth does not imply that bond refunding decisions are irrelevant. Incorrect refunding decisions can decrease stockholder wealth (see also Ofer and Taggart (1980)). 
The analysis holds regardless of whether the replacement bond is callable. Since a noncallable bond is a special case of a callable bond, refunded bonds are assumed to be replaced by callable bonds (which is closer to reality since most bonds are callable).

\section{Notations}

The notations employed in the paper are summarized below. ${ }^{6}$

$D_{t}=$ the price of the callable bond at time $t$ before the option to call at $t$ expires; time is measured from the date of issue of the existing bond;

$D_{t}^{\prime}=$ the price of the callable bond at time $t$ after the option to call at $t$ expires; i.e., $D_{t}^{\prime}$ is the price of a bond similar to the existing bond except that the earliest it can be called is at $(t+1)$;

$B_{t}=$ the price at time $t$ of a noncallable bond that is similar to the existing callable bond in every other respect;

$C=$ the call price of the existing bond; ${ }^{7}$

$F=$ the face value of the existing bond;

$c=$ the coupon rate of the existing bond;

$r_{i}=$ the coupon rate of the new issue if refunding takes place at time $i$;

$V_{o t}=$ the value of the firm at time $t$ if it is financed only by equity;

$R c_{t}, \delta c_{t}, K c_{t}=$ present values of interest tax shields, future call premium tax shields, and current and future after-tax transaction costs, respectively, if the firm calls the existing bond at time $t$ and follows the optimal refunding policy in the future;

$R n_{t}, \delta n_{t}, K n_{t}=$ present values of interest tax shields, call premium tax shields, and after-tax transaction costs, respectively, if the firm does not call the existing bond at time $t$ and follows an optimal refunding policy in the future;

$\tau=$ corporate tax rate;

$(y)_{q}=$ cash flow of $y$ dollars at time $q$;

$(y)_{t}^{q}=$ cash-flow stream of $y$ dollars per period starting a time $t$ and ending at time $q$;

$[a, b]_{I}=$ set of all integers between $a$ and $b$ where $a, b \in I$, the set of integers; and

$P V=$ present value.

${ }^{6}$ Values of items subscripted by $t$ may also depend on the level of interest rates at time $t$. For notational simplicity, this dependence is not explicitly stated. In the Appendix, where the algorithm to solve the refunding problem is developed, the dependence on interest rates is clearly stated.

${ }^{7}$ For notational simplicity, it is assumed that the call price is independent of the time to maturity. In practice, many callable bonds have call prices decreasing over time. The refunding criterion and the accompanying algorithm are easily adapted to varying call prices. 


\section{Analysis}

If the firm forgoes its right to call the existing bond at time $t$, the value of the equity is

$$
V_{o t}-D_{t}^{\prime}+R n_{t}+\delta n_{t}-K n_{t}
$$

On the other hand, if it decides to call the bond at time $t$, the value of the equity is

$$
V_{o t}-C+R c_{t}+\tau(C-F)+\delta c_{t}-K c_{t}
$$

since in this case the market value of the bond equals the call price $C{ }^{8}$ Refunding the bond at time $t$ is optimal if and only if

$$
V_{o t}-C+R c_{t}+\tau(C-F)+\delta c_{t}-K c_{t}>V_{o t}-D_{t}^{\prime}+R n_{t}+\delta n_{t}-K n_{t}
$$

or

$$
D_{t}^{\prime}-C>R n_{t}-R c_{t}-\tau(C-F)+\delta n_{t}-\delta c_{t}+K c_{t}-K n_{t}
$$

While computation of the present values of the interest tax shields on the right-hand side of equation (3) appears to be difficult, considerable simplification is possible if the risk of the interest tax shield cash flows is assumed to be the same as the risk of the bondholder cash flows. This assumption is common in the corporate finance literature and is used by Ofer and Taggart (1977) and Lewellen and Emery (1980) to analyze bond refunding. Consider $R n_{t}$ the present value of interest tax shields if the firm's optimal decision at time $t$ is not to call. To compute $R n_{t}$, first write $D_{t}^{\prime}$ as:

$$
\begin{aligned}
D_{t}^{\prime}=P V\left\{(c F)_{t+1}^{q},(C)_{q}\right\}, & q \in[t+1, \infty]_{I} \\
=P V\left\{(c F)_{t+1}^{q},\left(r_{q} C\right)_{q+1}^{q_{1}},\left(C_{1}\right) \mathrm{q}_{1}\right\}, & q \in[t+1, \infty]_{I}, q_{1} \in[q+1, \infty]_{I} \\
=P V\left\{(c F)_{t+1}^{q},\left(r_{q} C\right)_{q+1}^{q_{1}},\left(r_{q_{1}} C_{1}\right)_{q_{1+1}}^{q_{2}}, \ldots\right\}, & q \in[t+1, \infty]_{I}, q_{1} \in[q+1, \infty]_{I} \\
& q_{2} \in\left[q_{1}+1, \infty\right]_{I}
\end{aligned}
$$

The first equation states that $D_{t}^{\prime}$ is the present value of $(q-t)$ periodic interest payments and the call price in period $q$ if the current issue is called in period $q$, where

${ }^{8}$ It is implicitly assumed that the value of the equivalent all-equity firm, $V_{o t}$, is not affected by the refunding decision. This is a reasonable assumption since $V_{o t}$ represents the present value of the operating cash flows. This does not mean that interest rate realization (which underlies the refunding decision) has no bearing on the value of the firm's assets. Any such effect is already incorporated in $V_{o t}$. 
$q$ takes integer values greater than or equal to $(t+1) .^{9}$ The second equation rewrites $C$, the call price of the current bond and the face value of the first replacement bond, as the present value of its $\left(q_{1}-q\right)$ periodic interest payments $r_{q} C$ and its call price $C_{1}$ in period $q_{1}$, if it is called in period $q_{1}$, where $q_{1}$ takes integer values greater than or equal to $(q+1)$. The third equation simply extends this argument to all possible future refunding decisions. Since $R n_{t}$ is clearly $\tau$ times the righthand side of the last equation, it is equal to $\tau D_{t}^{\prime}$. By using the same argument it is easy to show that $R c_{t}=\tau C .^{10}$

Condition (3) can now be rewritten as

$$
\left(D_{t}^{\prime}-C\right)(1-\tau)+\tau(C-F)>\delta n_{t}-\delta c_{t}+K c_{t}-K n_{t}
$$

If it is optimal to call the bond, the bond is priced at $C$; if not, it is priced at $D_{t}^{\prime}$. Criterion (4) has a simple interpretation. The first term on the right-hand side is the present value of after-tax savings in interest payments from refunding and the second term is the current call premium tax shield. The left-hand side represents the difference in future call premium tax shields and transaction costs between not refunding and refunding. Thus, it is optimal to call if the sum of the present value of after-tax savings in interest payments and the current call premium tax shield exceeds the sum of the present values of incremental transaction costs and future call premium tax shields.

Refunding criterion (4) is recursive. To implement it, the value of a comparable callable bond with one-period call protection needs to be computed. But the evaluation of this comparable bond is based on the optimal call policy of that bond, which in turn depends on the valuation of yet another callable bond, and so on. That is, a series of callable bonds must be valued and their optimal call policies simultaneously determined. This can be done (in principle) by backward induction, starting from the period just before maturity.

${ }^{9}$ The calculation of the expected cash flow involves a set of future call probabilities that has not been explicitly included in the present value expression for notational simplicity. The appropriate discount rate(s) (which are determined partially by the call probabilities) are not mentioned since they are not consequential to the analysis as long as they reflect the risk of both the bond cash flows and the interest tax shields.

${ }^{10}$ Such simplification in the evaluation of $R n_{t}$ and $R c_{t}$ is possible only because the firm's capital structure objective specifies that the face value of the replacement bond equals the call price of the original bond. If, on the other hand, the firm's capital structure objective is to keep the face value of the debt constant, the present value of the interest tax shields is

$$
R n_{t}=\tau \times P V\left\{(c F)_{t+1}^{2},\left(r_{q} F\right)_{q+1}^{q_{1}}, \ldots\right\}
$$

This expression is more difficult to evaluate. The above expression cannot be written as $\tau$ times the present value of a callable bond with call price equal to $F$, since such a callable bond has associated with it a set of call probabilities that is different from the call probabilities of the existing bond (unless the call premium on the existing bond is zero). 


\section{Extensions and Generalizations}

Suppose the capital structure objective is to keep interest payments constant. " Equations (1), (2), and (3) still hold, but now $R n_{t}=R c_{t}$ since interest payments do not depend on the refunding decision. Therefore, refunding is optimal if and only if

$$
\left(D_{t}^{\prime}-C\right)+\tau(C-F)>\delta n_{t}-\delta c_{t}+K c_{t}-K n_{t}
$$

The only difference between criteria (4) and (5) is that the reduction in aftertax interest payments from refunding is now greater $\left(\left(D_{t}^{\prime}-C\right)\right.$ instead of $\left(D_{t}^{\prime}-C\right)$ $(1-\tau))$. To hold interest payments constant, the firm issues more debt than it refunded. This results in additional interest tax shields, increasing the advantage of refunding.

As stated earlier, it is immaterial whether the new issue is callable since a noncallable bond is equivalent to a callable bond with an infinite call price. Equations (1), (2), and (3) hold regardless of whether the new issue is callable. The relationships $\tau D_{t}^{\prime}=R n_{t}$ and $\tau C=R c_{t}$ are still valid since they do not depend on any specific set of call probabilities. Just as the interest tax shield of a noncallable bond is lower than that of a callable bond because of lower coupon payments, so are the discount rates. Therefore, the present value of the interest tax shield of a noncallable bond is equal to that of a callable bond. Also, $\delta c_{t}=0$ if the replacement bond is noncallable. Hence, the refunding criterion is to call if and only if

$$
\left(D_{t}^{\prime}-C\right)(1-\tau)+\tau(C-F)>\delta n_{t}+K c_{t}-K n_{t}
$$

If the decision horizon of the firm is infinite, the assumption that all bonds are perpetual can also be relaxed. The difference between bonds of finite and infinite maturities is that the former might not be called during its lifetime. If that happens, suppose the firm replaces the bond with another of equal face value. It is easy to show in this case that the value of the current bond can be written as the present value of a series of interest payments. It follows that the present values of the interest tax shields, $R c_{t}$ and $R n_{t}$, are again $\tau D_{t}^{\prime}$ and $\tau C$, respectively. Therefore, finite maturities do not affect the refunding criterion.

In perfect markets, if the interest rate equals the critical interest rate (the lowest rate at which it is optimal to call), shareholders are indifferent between calling and not calling, since the value of the bond equals the call price in either case. This is not true in the presence of imperfections such as taxes and transaction costs. To see this, consider the case where the replacement bond is noncallable. The refunding criterion, given by equation (6), can be rewritten as follows:

$$
D_{t}^{\prime}>C+\left[-\tau(C-F)+\delta n_{t}+K c_{t}-K n_{t}\right] /(1-\tau)
$$

${ }^{11}$ Under this capital structure objective, excess funds are available after the refunding operation since a higher face value of debt can be supported at the lower interest rate. Following other refunding papers, the excess funds so generated are assumed to be invested in a zero net present value project. 
Since the replacement bond is assumed to be noncallable, the call premium tax shield and transaction costs occur only once. Therefore, because of the time value of money, $K c_{t}>K n_{t}$ and $\tau(C-F)>\delta n_{t}$. If the effect of the call premium tax shield dominates that of the transaction costs, (7) reduces to $D_{t}^{\prime}>C-\varepsilon$, where $\varepsilon>0$. Suppose $D_{t}^{\prime}=C-\varepsilon$. Then, stockholders are indifferent between calling and not calling. If they decide to call, the bond is valued at $C$; otherwise, the bond is valued at $D_{t}^{\prime}<C$. In this case, where calling and not calling are equally probable, the bond is valued at $\left(D_{t}^{\prime}+C\right) / 2<C$ before the decision; i.e., the bond is priced below the call price just before a call. Similarly, if transaction costs dominate the call premium tax shield, the bond is priced above the call price just before a call. $\mathrm{Vu}$ (1986) finds evidence that bonds are priced both above and below the call price one month before the call, though the majority of the bonds in his sample are priced below the call price before the call, indicating that the effect of the call premium tax shield dominates that of transaction costs on average.

\section{Outline of the Methodology}

To illustrate the important ideas of the methodology, refunding criterion (6), which is derived under objective (c) by assuming that the replacement bond is noncallable, is implemented. If transaction costs are ignored, (6) reduces to

$$
\left(D_{t}^{\prime}-C\right)(1-\tau)+\tau(C-F)-\delta n_{t}>0
$$

In fact, the method developed here can easily accommodate transaction costs if they are either certain or a function of interest rate and time.

The outline of the methodology is as follows. $D_{t}^{\prime}$ and $\delta n_{t}$ are values of the bond and the call premium tax shield, respectively, if the bond is not called at $t$. Their values depend on $r, t$, and future call decisions. Thus, they can be valued on a recursive basis starting at maturity when the call decision is simple, i.e., do not call the bond. Once $D_{t}^{\prime}$ and $\delta n_{t}$ are computed, the refunding criterion is used to determine the current call policy. Then, using the rule that the value of the bond is $C$ if it is optimal to call and $D_{t}^{\prime}$ if it is not, the value of the bond is computed.

The complete methodology is provided in the Appendix. The key difference between this methodology and that of Brennan and Schwartz (1977) is the way the value of the callable bond is calculated. They use the finite difference approximation to calculate $D_{t}$, forcing it to the call price if it exceeds the call price. In contrast, the methodology presented here computes $D_{t}$ by the condition " $D_{t}$ equals $C$ if optimal to call, and equals $D_{t}^{\prime}$ otherwise." This subtle difference, however, enables the methodology to include corporate taxes and transaction costs. The Brennan and Schwartz methodology cannot be similarly extended because they use the boundary condition $D_{t}=C$ to force the value of the callable bond down to $C$. This condition always holds in efficient markets regardless of whether the firm pays taxes, or whether transaction costs are involved. The methodology of calculating $D_{t}^{\prime}$ and using the appropriate refunding criteria between equations (4) and (8) to calculate the critical interest rate and $D_{t}$ is more general and can accommodate taxes and transaction costs. 


\section{Comparative Statics}

The critical interest rate and the value of a callable bond with 8 percent annual coupon and fifteen years to maturity are calculated using the methodology described in the Appendix. The critical interest rate is computed as a function of the time to maturity for various values of $\sigma^{2}, C$, and $\tau$. Results are shown in Figures I-III. Figure I shows the impact of the call price on the critical interest rate. As expected, the critical interest rate decreases as the call price increases. The more interesting result is that when the call price is greater than the face value, the critical interest rate is a decreasing function of time to maturity for long maturities but an increasing function of time to maturity for short maturities. However, if the call price equals the face value, the critical interest rate is a monotonically decreasing function of time to maturity. It is well known that the option value increases with time to maturity. This option value is lost at the time of call; to make the call worthwhile, the underlying asset (the equivalent noncallable bond) must be sufficiently valuable. Therefore, as the option value decreases (as maturity approaches), a smaller drop in the interest rate makes the equivalent noncallable bond sufficiently valuable to make calling optimal. This effect dominates at larger maturities and hence the critical interest rate increases as maturity approaches. Near maturity, the value of the equivalent noncallable bond is very close to its face value. If the call price is greater than the face value, the premium paid to obtain this underlying asset through a call is justified only if the interest rate is sufficiently low. The shorter the maturity is, the lower the probability is that the value of the equivalent noncallable bond is significantly different from the face value. This effect dominates close to maturity and the critical interest rate drops as maturity approaches. If there is no call premium, the second effect is absent and the critical interest rate increases monotonically as maturity approaches.

Figure II shows the effect of changes in the volatility of interest rates on the critical interest rate. As $\sigma$ increases, the value of the option increases and the critical interest rate decreases. Not surprising, this effect is more pronounced the longer the time to maturity.

Figure III illustrates the effect of tax rates. While the higher the corporate tax rate is the higher the critical interest rate, the effect of taxes is negligible at longer maturities. Note that there are two tax effects: one due to the interest tax shield and the other due to the call premium tax shield. The former reduces the advantage of refunding $\left(D_{t}^{\prime}-C\right)$ by the factor $(1-\tau)$ (see equation (8)). Concerning the call premium tax shield, what really matters is $\tau(C-F)-\delta n_{t}$, the difference between the present values of the call premium tax shields if called now and if called (optimally) later. This difference is always positive since $\delta n_{t}$ is the present value of $\tau(C-F)$, discounted from the time the bond is called in the future. Thus, the call premium tax shield provides an incentive to refund. As maturity approaches, the probability of being called in the future reduces and $\delta n_{t}$ tends to zero. Thus, the effect of the call premium tax shield is more pronounced as maturity approaches. Moreover, since $D_{t}^{\prime} \simeq B_{t} \simeq F<C$ as maturity approaches $\left(D_{t}^{\prime}-C\right)$ is likely to be negative, and the interest tax shield reduces the disadvantage of refunding by the factor $(1-\tau)$. Therefore, as maturity approaches, tax effects increase the pro- 


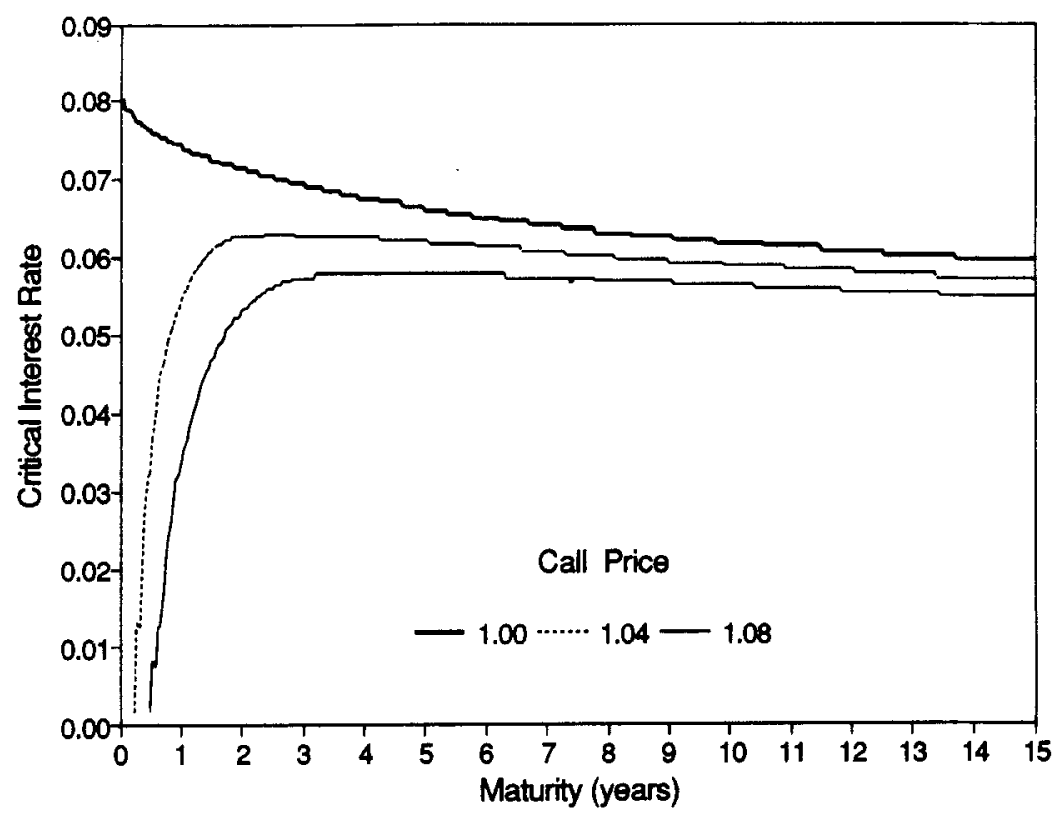

Figure I. Effect of Call Price $C$ on the Critical Interest Rate. $\sigma^{2}=0.002 ; c=8 \% ; \tau=0.34$

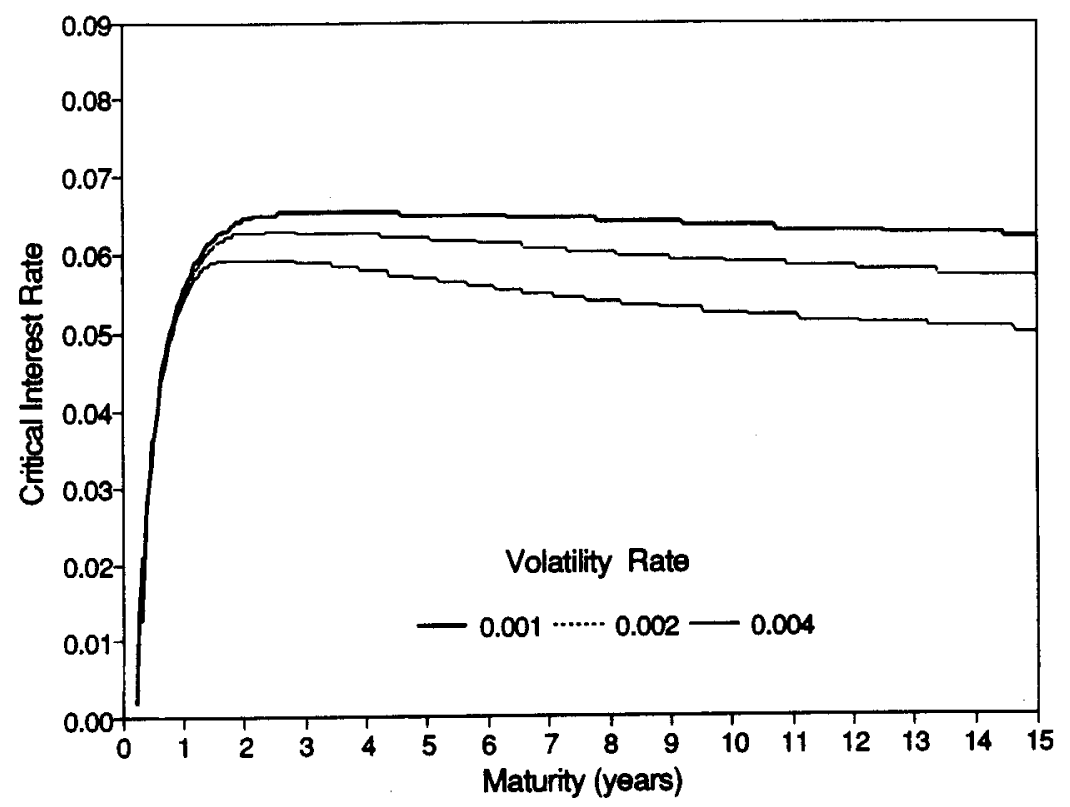

Figure II. Effect of Interest Rate Volatility $\sigma^{2}$ on the Critical Interest Rate. $C=1.04 ; c=8 \% ; \tau=0.34$ 


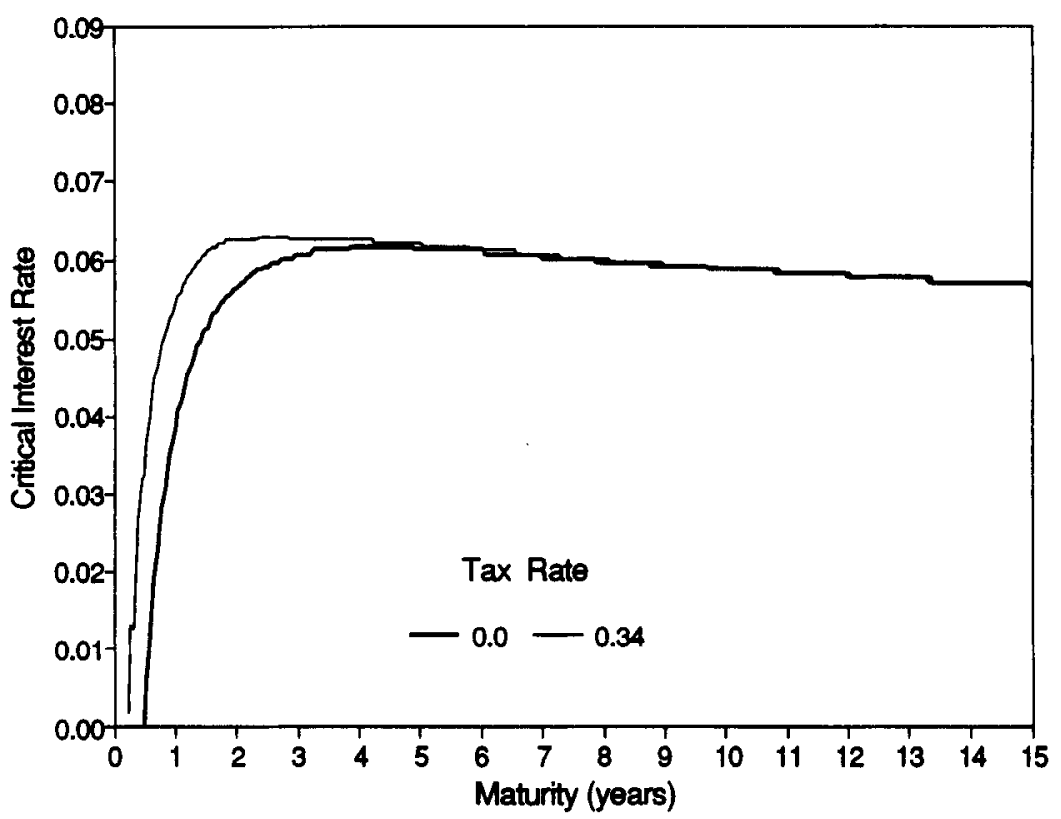

Figure III. Effect of Tax Rate $\tau$ on the Critical Interest Rate. $C=1.04 ; c=8 \% ; \sigma^{2}=0.002$

bability of call, thus increasing the critical interest rate. At longer maturities, $\tau(C-F) \simeq \delta n_{t}$ at the critical interest rate since, if the bond is not called now, it will almost surely be called in the near future. Hence, the effect of the call premium tax shield is negligible. Once this effect is eliminated, interest tax shields do not affect refunding since $(8)$ reduces to $\left(D_{t}^{\prime}-C\right)>0$. Thus, at longer maturities the critical interest rate is more or less unaffected by taxes.

\section{Comparison with Other Published Refunding Criteria}

The fundamental differences between the refunding criteria stated in equations (4) through (6) and the previously published criteria become apparent when they are compared under the Modigliani-Miller (MM) framework (perfect market without taxes or transaction costs). Such a comparison abstracts from changes in firm value due to capital structure changes during refunding and thus avoids the controversy and complication of what constitutes "pure refunding" (see Yawitz and Anderson (1977), Lewellen and Emery (1980)). Under MM conditions, the criteria in this paper reduce to "refund if $D_{t}^{\prime} \geq C$."

The criteria in Ofer and Taggart (1977), Yawitz and Anderson (1977), and Lewellen and Emery (1980) reduce under MM conditions to "refund if and only if the price of an equivalent noncallable bond is greater than or equal to the call price." In the notations of this paper, this criterion can be stated as $B_{t} \geq C$ and it coincides with this paper's criterion under MM conditions if and only if $B_{t}=D_{t}^{\prime}$. 
This happens only if the call option expires at time $t$ and the bond cannot be called in subsequent periods. Hence, the previous models assume that the call option expires if the bond is not called in the current period, which is why they are called static models.

It is easily verified that $B_{t} \geq C$ cannot be an optimal refunding criterion if the call option does not expire at $t$. Suppose it is an optimal refunding criterion. If $B_{t}$ equals $C$ at $t$, the market expects the bond to be called and prices it at $C$. Since $D_{t}^{\prime} \leq B_{t}$, with the strict inequality holding when the call option does not expire at time $t, D_{t}^{\prime} \leq C$. The stockholders now gain by not calling the bond. Once they decide to forego their option to call, the bond price drops to $D_{t}^{\prime}$, resulting in an arbitrage gain of $\left(C-D_{t}^{\prime}\right)$ to stockholders. Since arbitrage is possible by following an alternative strategy, the original refunding criterion $B_{t} \geq C$ cannot be optimal (see also Livingston (1987)).

To see the inconsistencies in the Kraus (1973) model, consider its decision criterion one period before maturity, when it is essentially a static one. In a static model, the bond is called if $B_{t} \geq C$, and in the special case where the call price equals the face value, it is called if the current interest rate is less than the coupon rate. The Kraus model, however, does not automatically recommend refunding under these circumstances, but argues that the refunding decision depends on the expected future interest rate. Also, the Kraus model implies that, even in an MM world, refunding a noncallable bond (by paying the market price) is a nontrivial issue. But clearly this is not true in an MM world, where no financial transaction can affect shareholder wealth. These inconsistencies are the result of the model's objective function that minimizes "debt costs" instead of maximizing shareholder wealth. Given this objective, it is not clear why the firm issued any kind of debt in the first place since debt costs can be eliminated by not issuing debt. (Since there is no corporate tax in the Kraus model, it cannot be cited as an incentive for issuing debt.) Finally, using a single risk-free rate of interest to discount cash flows in different periods is inappropriate since the risk-free rate is stochastic.

Since $D_{t}=C$ whenever it is optimal to call, some textbooks (see Brealey and Myers (1988)) state that the optimal call policy is to call when $D_{t}=C$. Stating optimal call policies in terms of the bond price $D_{t}$ is misleading for two reasons. First, $D_{t}$ itself is determined by the call policy of the firm and therefore making the call policy depend on $D_{t}$ leads to a circular argument. Second, in an efficient market many call policies (not necessarily optimal) lead to the conclusion "call if $D_{t}=C$." For example, suppose a firm follows the policy of calling if $B_{t} \geq C$, i.e., if the price of a similar noncallable bond is greater than the call price. If at time $t$ the state variables take on values such that $B_{t} \geq C$, the market realizes that the bond will be called and prices it at $C$. If $B_{t}<C$, the market knows that the bond will not be called. The price of the callable bond is then less than or equal to $B_{t}$ since the call option cannot have a negative value. It follows that the callable bond will be priced strictly lower than $C$. Thus, even this call policy (which has been shown to be suboptimal except when it is the last opportunity to call), can be restated as "call if bond price equals call price." Moreover, because corporate bonds are thinly traded, quoted prices often do not reflect true values. Therefore, it is more meaningful to state the refunding policy in terms other than $D_{t}$. 


\section{Summary}

In this paper the bond refunding decision is analyzed in an efficient market as a dynamic optimization problem under the objective of shareholder wealth maximization. The analysis also considers the effect of corporate taxes and transaction costs. Refunding criteria are derived under different capital structure objectives and an algorithm for implementing them using numerical techniques is presented. Critical interest rates are calculated for a specific stochastic process of interest rates. Comparative statics, illustrating the effect of call price, volatility of interest rates, and tax rates on the refunding decision, are derived. The methodology presented here is general enough to be adapted to different stochastic processes.

\section{Appendix}

\section{Implementation of the Methodology}

The interest rate is assumed to follow a continuous-time stochastic process and the pure (local) expectation hypothesis is assumed to hold so that the instantaneous expected return on default-free securities of all maturities equals the instantaneous risk-free rate. The same stochastic process as in Brennan and Schwartz (1977) is used for comparison:

$$
d r=r \sigma d z
$$

where $d z$ is a Gauss-Weiner process. Define the discount factor $s \equiv 1 /(1+r)$. Let $D(s, T)$, where $T$ is the time to maturity, represent the value of a default-free callable bond. Suppose this bond has a face value of one and a call price of $C$, and pays coupon continuously at the rate of $c$.

Let $G(s, T)$ represent the present value of a generic security that provides a one-time future cash flow that occurs no later than $T$ periods, and a continuous coupon payment at the rate of $c$. Then, $G(s, T)$ is the solution to a partial differential equation, the finite difference approximation of which is represented by the set of equations

$$
\begin{aligned}
U_{i} G_{i-1, j}+V_{i} G_{i, j}+W_{i} G_{i+1, j}=G_{i, j-1}+c k \quad i=1, \ldots,(n-1), & \\
j & =1, \ldots, m,
\end{aligned}
$$

and a set of boundary conditions that specifies the nature of the cash flow, where,

$$
\begin{aligned}
U_{i} & =-1 / 2 \sigma^{2} k i^{2}(1-i h)^{2}+1 / 2 \sigma^{2} k i(1-i h)^{2} \\
V_{i} & =\sigma^{2} k i^{2}(1-i h)^{2}+(1-i h) k / i h+1 \\
W_{i} & =U_{i}-\sigma^{2} k i(1-i h)^{2}
\end{aligned}
$$




$$
\begin{aligned}
h & =1 / n \\
G(s, T) & =G(i h, j k)=G_{i, j}
\end{aligned}
$$

$h$ and $k$ are discrete increments of the discount factor and time to maturity; $i$ and $j$ are the indices to the discount factor and the time to maturity. $i=n$ implies that the discount factor is one (interest rate is zero), and $i=0$ implies that the discount factor is zero (interest rate is infinity). Similarly, $j=0$ implies that the bond is at maturity and $j=1$ means that it is one period before maturity and so on. If the value of the security as the interest rate tends to infinity is known, the set of equations (A2) reduces to

$$
u_{i j} G_{i, j}+v_{i j} G_{i+1, j}=w_{i j}, \quad i=1, \ldots,(n-1), j=1, \ldots, m,
$$

where $u_{i j}, v_{i j}$, and $w_{i j}$ are functions of $U_{i}, V_{i}, W_{i}, c$, and $G_{i, j-1}$. If the terminal value and the zero-interest value of the security are known, the value of $G$ for any interest rate and time to maturity can be calculated by proceeding recursively. The terminal value and the zero-interest value depend on the type of security.

For a noncallable bond $B(s, T)$, the three boundary conditions (infinite interest, zero interest, and terminal value), respectively, are:

$$
\begin{array}{lll}
B_{0, j}=0, & j>0 \\
B_{n, j}=1+c k j, & j>0 \\
B_{i, 0}=1, & i=0,1, \ldots, n
\end{array}
$$

Equation (A4) states that if the interest rate approaches infinity the bond value approaches zero. Condition (A5) reflects that when the interest rate is zero the bond value is the undiscounted sum of the face value and the coupon payments till maturity. This follows from the stochastic process (A1), which implies that once the interest rate hits zero it will stay at zero ( $r=0$ is an absorbing state). Condition (A6) states that bond value equals face value at maturity.

To implement refunding criterion $(8), D^{\prime}(s, T)$, the value of a one-period callprotected bond, and $\delta n(s, T)$, the value of the call premium tax shield if the bond is not called today but is called optimally in the future, need to be calculated. If the decision is to call, the value of the callable bond $D(s, T)$ equals $C$. If the decision is not to call, $D(s, T)=D^{\prime}(s, T)$. For clarity, refunding criterion (8) is restated in its finite difference form:

$$
\left(D^{\prime}(j)_{i, j}-C\right)(1-\tau)+\tau(C-1)-\delta n(j)_{i, j}>0
$$

In (A7), $D^{\prime}(j)_{i, j}$ represents the value at $(i, j)$ of a bond call protected for one period from $j$, and $\delta n(j)_{i, j}$ represents the value of the call premium tax shield at $(i, j)$ if the bond is not called at $j$ but is called optimally in the future.

$B_{n, j}$, the value of a noncallable bond at zero interest rate, equals $(1+c k j)$, since the stochastic process (A1) has an absorbing state at $i=n$. Since $B_{n, j} \geq$ $D^{\prime}(j)_{n, j}$ if 


$$
\left(B_{n, j}-C\right)(1-\tau)+\tau(C-1)<0
$$

it follows from (A7) that it is not optimal to call at $j$ when the interest rate is zero. Hence, it is not optimal to call at higher interest rates. Therefore, if (A8) holds, it is not optimal to call the bond at $j$, whatever the interest rate.

Define $j^{*}$ as follows:

$$
j^{*}=\min \{j \mid(1+c k j-C)(1-\tau)+\tau(C-1) \geq 0\}
$$

For $j<j^{*}$, (A8) holds and it is not optimal to call. (For bonds with declining call prices, $\left.j^{*}=0.\right)^{12}$ Hence, for these values of $j, D_{i, j}=D^{\prime}(j)_{i, j}=B_{i, j}$, for all $i . B_{i, j}$ can be evaluated from (A3) using boundary conditions (A4) to (A6).

For $j=j^{*}, D^{\prime}\left(j^{*}\right)_{n, j^{*}}=B_{n, j^{*}}=1+c k j^{*}$, since the one-period call-protected bond is called at all. Also, $\delta n\left(j^{*}\right)_{i, j^{*}}=0$ for all $i$, since there are no future calls. (A3) and the following boundary conditions are used to evaluate $D^{\prime}\left(j^{*}\right)_{i, j^{*}}$ for $i=n-1, \ldots, 1$ :

$$
\begin{aligned}
D^{\prime}\left(j^{*}\right)_{n, j^{*}} & =1+c k j^{*} \\
D^{\prime}\left(j^{*}\right)_{0, j^{*}} & =0 \\
D^{\prime}\left(j^{*}\right)_{i, j^{*-1}} & =B_{i, j^{*-1}}
\end{aligned}
$$

(A9) is the zero-interest condition, (A10) is the infinite-interest condition, and (A11) is the terminal-value condition. (A11) follows from the fact that a bond, protected from call for one period from $j^{*}$, is called in the future by the definition of $j^{*}$. Thus, its value at $j^{*}-1$ is that of a noncallable bond. Once $D^{\prime}\left(j^{*}\right)_{i, j^{*}}$ is known, $D_{i, j^{*}}^{\prime}$ is calculated using (A7).

For $j>j^{*}, D^{\prime}(j)_{n, j}=C+c k$ since the one-period call-protected bond will certainly be called next period if the current interest rate is zero. This is so since, by definition, when $j \geq j^{*}$, (A7) is satisfied at zero interest rate. $D_{i, j}^{\prime}$ is evaluated using (A3), the boundary conditions (A10), and:

$$
\begin{aligned}
D^{\prime}(j)_{n, j} & =C+c k \\
D^{\prime}(j)_{i, j-1} & =D_{i, j-1}
\end{aligned}
$$

(A13) incorporates optimal future refunding. The value at $j-1$ of a bond protected from call for one period from $j$ is equal to that of an unprotected bond.

For $j>j^{*}, \delta n(j)_{i, j}$ is evaluated using (A3) and the following boundary conditions:

$$
\delta n(j)_{n, j}=\tau(C-1)
$$

${ }^{12}$ In practice, call prices usually vary with time. The common practice is to set the initial call premium equal to one year's coupon and then decrease it by a constant dollar amount each year such that the call premium decreases to zero by the last year of the bond's life (sometimes the call premium is reduced to zero for the last few years of the bond's life). Thus, $C_{j}$, the call price at $j$, is always smaller than $1+c k j$. This implies that $j^{*}=0$ for callable bonds with a decreasing call price. 


$$
\begin{aligned}
\delta n(j)_{0, j} & =0 \\
\delta n(j)_{i, j-1} & =\tau(C-1), \text { if } D_{i, j-1}=C \\
& =\delta n(j-1)_{i, j-1}, \text { otherwise }
\end{aligned}
$$

(A14) states that at zero interest rate, if the bond is not called today it will certainly be called next period and hence the present value of the future call premium tax shield is $\tau(C-1)$. (A15) implies that when the interest rate is infinity the present value of future call premium tax shields is zero. (A16) ensures that the tax shield is valued on the basis of optimal refunding in the future. In the next period, the call premium tax shield will be $\tau(C-1)$ in those states in which it is optimal to call. Therefore, in those states $\delta n(j)_{i, j-1}$ is forced to $\tau(C-1)$, leaving its values in all other states unaltered. Having computed $D^{\prime}(j)_{i, j}$ and $\delta n(j)_{i, j}$, (A7) is used once again to determine $D_{i, j}^{\prime}$. In this manner, the critical interest rate, i.e., the rate at or below which the bond should be called, and the value of the callable bond are determined simultaneously.

\section{References}

Bierman, H., 1966, The bond refunding decision as a Markov process, Management Science 12, 545-551.

Bowlin, O. D., 1966, The refunding decision: Another special case in capital budgeting, Journal of Finance 21, 55-68.

Brealey, R. and S. C. Myers, 1988, Principles of Corporate Finance, 3d ed. (McGraw-Hill, New York).

Brennan, M. J. and E. S. Schwartz, 1977, Savings bonds, retractable bonds and callable bonds, Journal of Financial Economics 5, 67-88.

Constantinides, G. M. and B. D. Grundy, 1987, Call and conversion of convertible bonds: Theory and evidence, CRSP working paper, University of Chicago.

Dunn, K. B. and C. S. Spatt, 1986, The effect of refinancing costs and market imperfections on the optimal call strategy and the pricing of debt contracts, Working paper, Carnegie-Mellon University.

Kalymon, B. A., 1971, Bond refunding with stochastic interest rates, Management Science 17, 171-183.

Kraus, A., 1973, The bond refunding decision in efficient markets, Journal of Financial and Quantitative Analysis 8, 793-806.

Lewellen, W. G. and D. R. Emery, 1980, On the matter of parity among financial obligations, Journal of Finance 35, 97-111.

Livingston, M., 1987, Measuring the benefit of bond refunding: The problem of non-marketable call options, Financial Management 16, 38-40.

Ofer, A. R. and R. A. Taggart, Jr., 1977, Bond refunding: A clarifying analysis, Journal of Finance 32, 21-30.

and R. A. Taggart, Jr., 1980, Bond refunding reconsidered: Reply, Journal of Finance 35, 197-200.

Pye, G., 1966, The value of the call option of a bond, Journal of Political Economy 74, 200-205.

Vu, J. D., 1986, An empirical investigation of calls of non-convertible bonds, Journal of Financial Economics 16, 235-265.

Weingartner, M. H., 1967, Optimal timing of bond refunding, Management Science 13, 511-524.

Yawitz, J. B. and J. A. Anderson, 1977, The effect of bond refunding on shareholder wealth, Journal of Finance 32, 1738-1746. 